University of Nebraska - Lincoln

DigitalCommons@University of Nebraska - Lincoln

2010

\title{
Finite Element Analysis of Cracks in Aging Aircraft Structures with Bonded Composite-Patch Repairs
}

\author{
Linxia Gu \\ University of Nebraska-Lincoln, gul@fit.edu \\ Ananth Ram Mahanth Kasavajhala \\ University of Nebraska-Lincoln \\ Shijia Zhao \\ University of Nebraska-Lincoln
}

Follow this and additional works at: https://digitalcommons.unl.edu/mechengfacpub

Part of the Mechanical Engineering Commons

Gu, Linxia; Kasavajhala, Ananth Ram Mahanth; and Zhao, Shijia, "Finite Element Analysis of Cracks in Aging Aircraft Structures with Bonded Composite-Patch Repairs" (2010). Mechanical \& Materials Engineering Faculty Publications. 42.

https://digitalcommons.unl.edu/mechengfacpub/42

This Article is brought to you for free and open access by the Mechanical \& Materials Engineering, Department of at DigitalCommons@University of Nebraska - Lincoln. It has been accepted for inclusion in Mechanical \& Materials Engineering Faculty Publications by an authorized administrator of DigitalCommons@University of Nebraska Lincoln. 
Published in Composites: Part B 42 (2011), pp. 505-510; doi: 10.1016/j.compositesb.2010.11.014

Copyright @ 2010 Elsevier Ltd. Used by permission. http://www.elsevier.com/locate/compositesb

Submitted July 9, 2010; revised October 2, 2010; accepted November 29, 2010; published online December 4, 2010.

\title{
Finite element analysis of cracks in aging aircraft structures with bonded composite-patch repairs
}

\author{
Linxia Gu, Ananth Ram Mahanth Kasavajhala, and Shijia Zhao
}

Department of Mechanical Engineering, University of Nebraska-Lincoln, Lincoln, NE 68588, United States

Corresponding author - L. Gu, tel 402 472-7680, fax 402 472-1465, email lgu2@unl.edu

\begin{abstract}
Bonded composite-patch repair has been used to transfer load from cracked structures to the reinforcement such that subsequent crack propagation is reduced. In this study, the mechanical behavior of a single edge v-notch Al7075-T6 plate repaired with 1-ply and 4-ply composite patches was investigated through the finite element method. Contour integral method was used to define and evaluate the stress intensity factors at the crack tip. The effect of the adhesive epoxy film, patch material, thickness and ply orientations on the evolution of the stress intensity factor (SIF) of the repaired structure was examined. The results indicated that the SIF of the notched plate is reduced by $1 / 6-1 / 20$ as a result of the bonded composite-patch repair. The crack mouth opening displacement (CMOD) is reduced even further by $80-83 \%$. Shear strength and thickness of the adhesive bond were the largest factors in the effectiveness of patch repair.
\end{abstract}

Keywords: Lamina/ply, Adhesion, Stress transfer, Stress intensity factor, Finite element analysis

\section{Introduction}

It is economical to use various crack repair techniques to regain the load-carrying capability of cracked components and to extend the service life of aging aircraft, particularly when the crack size is relatively small. The use of bonded composite patches to repair damaged aircraft and marine structures was first initiated by Baker [1]. They have been successfully used on military aircraft for many years due to their high strengths, specific stiffness, longer fatigue life, corrosion and wear resistance [2]. However, as composite patches were bonded to the metallic plate surfaces symmetrically (double patch) or asymmetrically (single patch), the plate would develop highly complicated three-dimensional stresses. Thus, prediction of the behavior of repaired structures remains a challenge under inplane loading.

Finite element method (FEM) provides a powerful means to conduct virtual experiments and analyze the behavior of the cracked plate under various configurations. It has been one of the most prevalent numerical tools in the field of fracture mechanics since the early 1960s. Researchers have been developing new techniques to improve the accuracy of FEM in application to fracture mechanics [3-11]. The use of quarter point elements in improving the accuracy of the solution around the crack tip was suggested by Henshel and Shaw [12] and Barsoum [13]. Murti et al. [11] took this study further by developing several other element types to increase the accuracy of the SIF calculation. Megueni et al. [14] used the quarter point element in their finite element model of the cracks repaired with bonded composite patches. They found out that the stress intensity factors are reduced with a thicker patch, thereby reducing the negative effect of disbond. A similar computational study conducted by Umamaheswar and Singh [15] also suggested a direct relationship between the adhesive thickness and reduction in SIF. When SIF is the determinant of the amount of damage, it may lead to structural failure as it grows beyond fracture toughness of the material [16]. Experimental static and fatigue tests conducted by Wang and Pidaparti [17] revealed a 10 fold increase in fatigue life and 2-4 times decrease in stress intensity factor, by repairing an Al7075-T6 pre-cracked specimen with 4-ply boron/epoxy composite patch.

Most of computational models of the composite-patch-repaired plates utilized a simplified two-dimensional model [3, $4,8,14]$. However a plate under in-plane loading would develop highly complicated three-dimensional stresses if patches are bonded to its surfaces regardless of single or double sided patch. This will become more difficult to predict the behavior of the repaired plate and the subsequent derivation of SIF.

In the present paper, three-dimensional finite element models, with reasonably low aspect ratio elements at the crack tip, has been developed to quantify the performance of pre-cracked Al7075-T6 Single Edge Notch Tension (SENT) specimen repaired with various bonded composite patches. The load transfer mechanisms from the aluminum plate to the patch, the effect of single and double sided repairs, initial crack length, adhesive shear modulus, adhesive thickness, patch material, patch thickness, and fiber orientation on the reduction of the SIF and mode I crack opening has been investigated. 


\section{Geometry and materials}

A model of a three-dimensional plate with height $h=305$ mm, width $w=51 \mathrm{~mm}$, thickness $t=1.6 \mathrm{~mm}$, a pre-existent crack of length $a=8 \mathrm{~mm}$, and crack mouth opening of $0.5 \mathrm{~mm}$ was created, as shown in Figure 1. The adhesive and the patch are denoted using subscripts $a$ and $p$, respectively. A rectangular patch and adhesive with the dimensions $h_{p}=h_{a}=117 \mathrm{~mm}$, $w_{p}=w_{a}=w=51 \mathrm{~mm}, t_{p}=0.66 \mathrm{~mm}$, and $t_{a}=0.12 \mathrm{~mm}$ has been used. The optimum thickness for a patch was adapted from [18] as

$$
E_{p} t_{p}=E t
$$

where $E$ is the modulus of elasticity of the $\mathrm{Al}$ plate, $E_{p}$ is modulus of elasticity of the composite patch, $t$ is thickness of the plate, and $t_{p}$ is the thickness of the patch.

The above relation is valid only for pure tension loads. For optimum results, it is suggested to take a patch with dimensions 4-5 times the length of the crack [18]. In this study, the effect of crack length on the crack behavior has been studied by varying the crack length as $9 \%, 15 \%, 19 \%, 29 \%, 39 \%$, and $49 \%$ of the plate width $(w)$. The material properties for the Al7075-T6 plate, FM 73 adhesive, boron/epoxy, and carbon/ epoxy pre-preg patches are summarized in Table 1.

\section{Finite element model}

The complete structure has been meshed using three-dimensional hex-dominated quadratic elements. The crack tip, because of its sharp edge, was modeled separately so as to create quarter point elements, converting the 20 node brick elements into 15 node wedge elements, by moving the mid side nodes to $1 / 4$ of the element length. The mesh created is shown in Figure 2. The Al plate is subjected to a uniform linear ramping pressure of $250 \mathrm{MPa}$ on one end while the other end is fixed to zero degrees of freedom, which is done to mimic the specimen under test condition. To ensure there is no relative motion between the plate and the patch, both of them are constrained by tying with the adhesive layer.

ABAQUS/CAE, a commercial nonlinear finite element code developed by SIMULIA Inc., was used to perform the analysis. Contour integral method was used to define the onset of cracking and was requested as an output parameter to calculate the SIF and J-integral at the crack tip. This method uses domain integral technique to expand the area integral in the two-dimensional case and volume integral in the three-dimensional case [21]. This technique provides a better result if a focused mesh is used at the crack and can even produce accurate results by using a coarse mesh. The variation of different fracture parameters by repairing the precracked $\mathrm{Al}$ substrate with single and double sided patches has been investigated.

\section{Results and discussions}

The SIF analytical solution $[22,23]$ was used to validate our computational results. The mode I SIF for a single edge notch specimen in tension [22] can be calculated by

$$
K_{1}=F(a / w) \sigma \sqrt{\pi a}
$$

where $\sigma$ is the applied nominal stress, $a$ is the edge crack length, and $F(a / w)$ is a dimensionless quantity that depend on the part's geometry, the type of loading and the ratio of crack length to the plate width $(a / w)$, which is obtained from experiments as

$$
F(a / w)=0.265(1-a / w)^{4}+\frac{0.857+0.265 a / w}{(1-a / w)^{3 / 2}}
$$

For the adhesive joint, Rose [23] has proposed a model (Equation 4) to calculate the mode I SIF of the 2D homogeneous isotropic singe sided patch-repaired plate, which was validated experimentally by Muller et al. [24].

$$
K_{p}=\frac{K_{1}}{1+S}\left[\frac{\Delta}{a+\Delta}\right]^{1 / 2}
$$

where $K_{p}$ is the mode I SIF of the repaired plate, $K_{1}$ is mode I SIF of SENT specimen, $S$ is a dimensionless quantity of both modulus of elasticity $E$ and thickness $t$ as $E_{p} t_{p} / E t$, and $\Delta$ is a size parameter that depends on both material properties (modulus of elasticity $E$ and shear modulus $G$ ) and thickness of the patch and plate, which is calculated as

$$
\Delta=\left[\frac{t_{a}}{G_{a}}\left(\frac{E_{p} t_{p} E t}{E_{p} t_{p}+E t}\right)\right]^{1 / 2}
$$
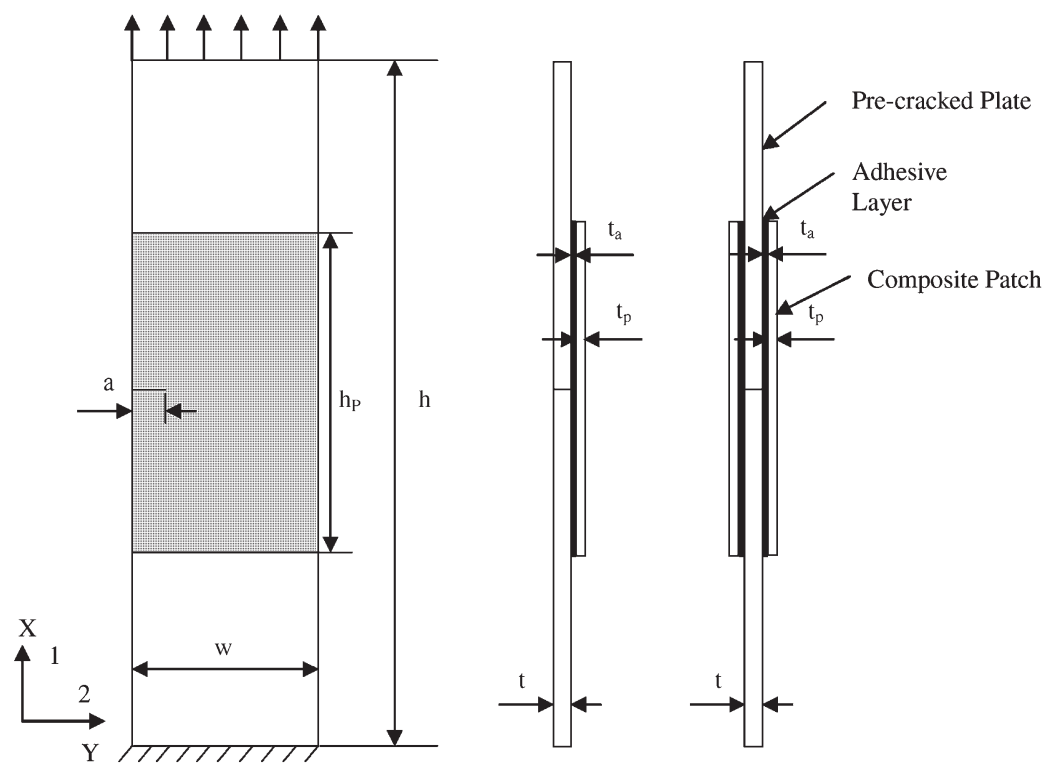

Figure 1. Geometrical model of the plate with single and double patch. 
Table 1. Material properties of cracked substrate, patches and adhesive [17, 19, 20].

\begin{tabular}{|c|c|c|c|c|}
\hline Properties & Al 7075 T6 & Boron/epoxy & Carbon/epoxy & FM73 adhesive \\
\hline Longitudinal modulus, $E_{1}(\mathrm{GPa})$ & 72 & 208 & 145 & 1.1 \\
\hline Transverse in-plane modulus, $E_{2}(\mathrm{GPa})$ & - & 25.4 & 10 & - \\
\hline Transverse out of plane modulus, $E_{3}(\mathrm{GPa})$ & - & 25.4 & 10 & - \\
\hline Out of plane shear modulus, $G_{13}(\mathrm{GPa})$ & - & 7.2 & 7 & - \\
\hline Out of plane shear modulus, $G_{23}(\mathrm{GPa})$ & - & 4.9 & 3.7 & - \\
\hline Major in-plane Poison's ratio, $v_{12}$ & 0.33 & 0.1677 & 0.25 & 0.44 \\
\hline Density $\left(\mathrm{g} / \mathrm{cm}^{3}\right)$ & 2.8 & 2 & 1.6 & 1.2 \\
\hline Yield stress (GPa) & 0.49 & 1.165 & - & - \\
\hline Ultimate strength (GPa) & 0.520 & 1.550 & - & 0.048 \\
\hline
\end{tabular}

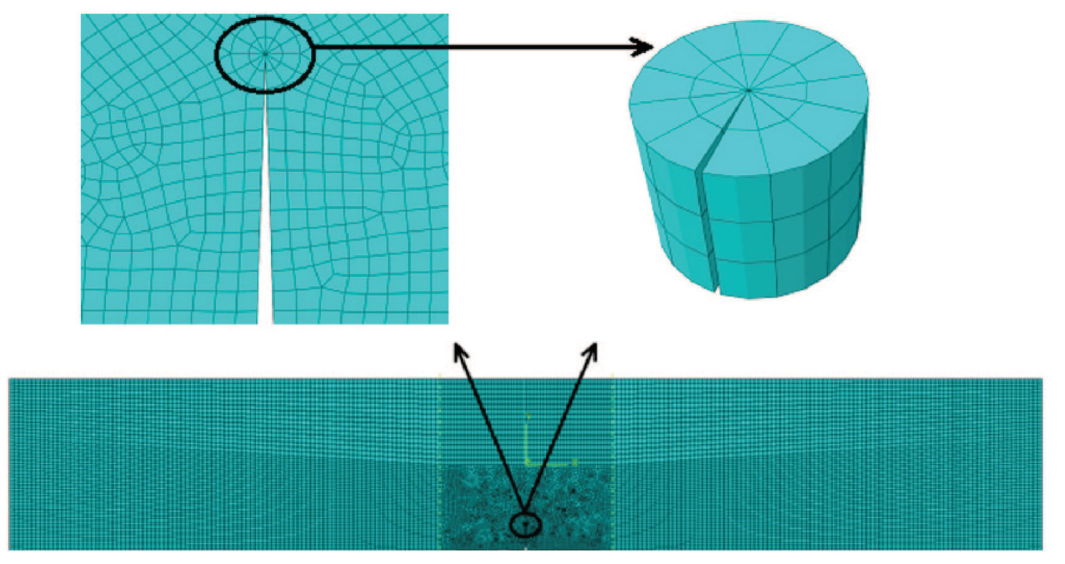

Figure 2. Finite element mesh.

The calculated mode I SIFs are $1616.77 \mathrm{MPa} \vee \mathrm{mm}$ for the bare plate and $440.88 \mathrm{MPa} \sqrt{ } \mathrm{mm}$ for $\mathrm{Al}$ plate bonded with single sided patch through a $0.12 \mathrm{~mm}$-thick adhesive layer. The SIF obtained from simulation are $1623.57 \mathrm{MPa} \sqrt{\mathrm{mm}}$ for the bare plate, $446.1 \mathrm{MPa} \sqrt{ } \mathrm{mm}$ for the repaired plate with an isotropic patch, It is clear that our SIF computational results agree well with the analytical solutions with a $0.42 \%$ deviation for bare plate and $1.2 \%$ deviation for repaired plate.

\subsection{Effect of single and double sided repair}

An un-notched $\mathrm{Al}$ plate was modeled first to obtain reference results identified as a baseline. A v-notched plate (bare plate) with an initial crack length $a=8 \mathrm{~mm}$ or $a / w=0.156$ was then repaired with 1-ply boron/epoxy patch through single and double sided repairs. Figure 3 shows a plot of load versus displacement where no strain hardening is specified. The perfect plastic deformation is clearly shown as the yield point is reached. Due to the presence of the crack in the plate, the notched plate has failed earlier before the yield point of the baseline has been reached. With the 1 -ply $0^{\circ}$ fiber (along the load direction $x$ ) direction patch bonded to the notched plate the stiffness of the repaired structure is increased. This thereby decreases the displacement at the point of yield with respect to the un-notched specimen (baseline). The double sided patch repair regains more of the load-carrying capacity than single sided repair.

A displacement profile over the crack is parabolic in nature in the crack tip region and linear away from the crack tip, as shown in Figure 4. The crack mouth opening displacement (CMOD) in the composite-patch-repaired plate is reduced by

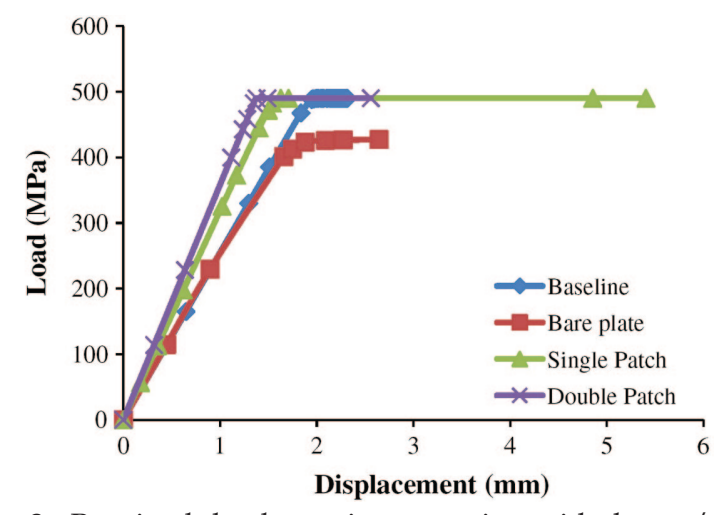

Figure 3. Regained load-carrying capacity with boron/epoxy patch repair.

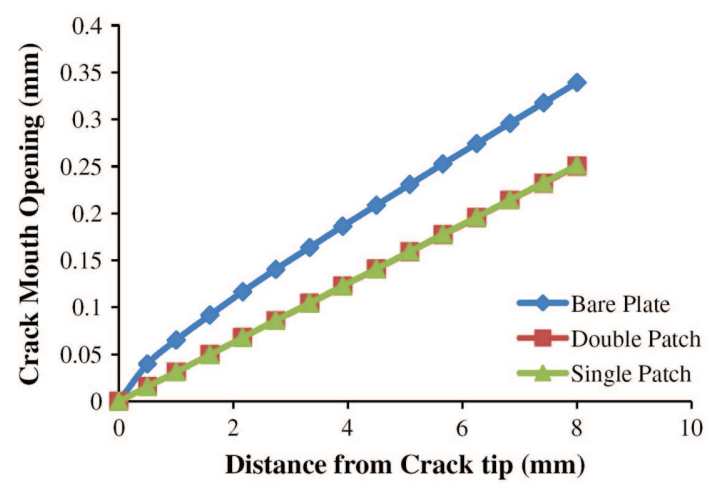

Figure 4. Crack profile for a plate repaired with boron/epoxy patch. 
$83 \%$ of that of the bare plate, even that difference between the single and double patch is in the order of few micrometers. This is due to the dominant stiffness of boron/epoxy patches along the load direction, which is three times that of the plate stiffness.

The uniaxial loading leads to a much larger mode I SIF, compared to mode II and III SIF, which could be neglected in this case. The damage of the notched plate will be quantified by mode I SIF only. The reduction in the mode I SIF is around 6-17 times that of a bare plate for single and double sided patch repairs, as shown in Table 2. This indicates that the patch is effective in decelerating the crack growth.

\subsection{Effect of initial crack length}

Boron/epoxy double patch repair reduces the SIF significantly due to the load-sharing capacity of the composite patch as demonstrated in Figure 5. The results indicate an asymptotic behavior of SIF as the crack length increases. Additionally, for $a / w=0.5$ there is 55 times reduction in the SIF for double patch repair with respect to the bare plate.

\subsection{Effect of patch material, number of plies, and orientation of plies}

Composite patch material plays a vital role in increasing the strength and thereby the service life of the repaired structure. Both the structural material to be repaired and the amount of damage govern the selection of the patch material. In this study, boron/epoxy and carbon/epoxy composite patch materials have been compared for the repair of cracked Al7075-T6 plate.

Figure 6 and Table 3 demonstrate that the SIF decreased $21 \%$ using boron/epoxy instead of carbon/epoxy. It is apparent that boron/epoxy provides better load sharing than carbon/epoxy pre-preg patches. This is due to its better stiffness in the longitudinal direction. There is nearly a three times reduction in the SIF by using a $0^{\circ}$ fiber orientation (perpendicular to the advancing crack) rather than a $90^{\circ}$ orientation (parallel to the emanating crack) as shown in Table 3.

The number of plies and ply orientation are two different factors which also influence the mechanical properties of the composite. The number of plies to be considered for a composite patch depends on the amount of damage, and the ply orientation depends on the direction in which the damage is present, and may subsequently progress, as well as the loading directions [19].

Under the assumption of a constant thickness of the composite patch, the 4-ply boron/epoxy is inferior to the 1-ply patch (Figure 6). This is due to the fact that the load is uniaxial along the fiber direction of the 1-ply patch. The 4-ply patch will be superior for multiaxial loading conditions. Table 3 clearly shows the increase of the SIF as the ply orientation is changed away from $0^{\circ}$ in $x$-direction. As the ply orientation varies from $0 / 30 / 30 / 0$ to $0 / 90 / 90 / 0$, the SIF increased by $20 \%$. This is because the effective elastic modulus of the composite patch is decreased in the direction perpendicular to the crack thereby increasing the SIF at the crack tip. In summary, the effectiveness of the ply orientation depends on the loading direction and the crack direction.

\subsection{Effect of a patch thickness}

Patch thickness depends on the level of cracking and the thickness of the damaged panel. A series of analysis have been performed by varying the composite patch thickness for

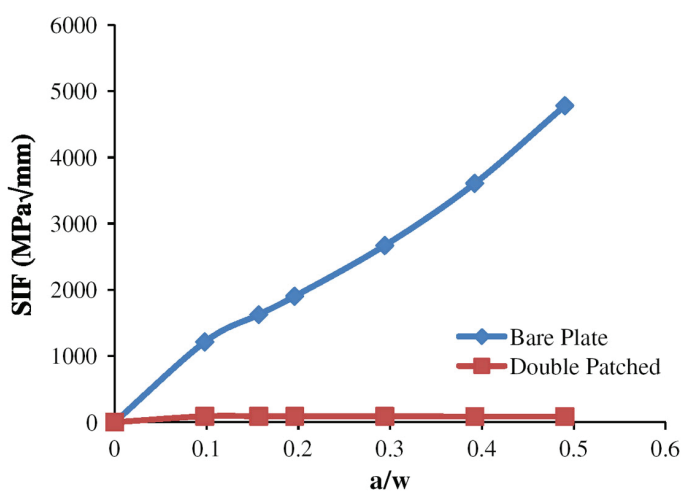

Figure 5. Effect of crack length on the SIF.

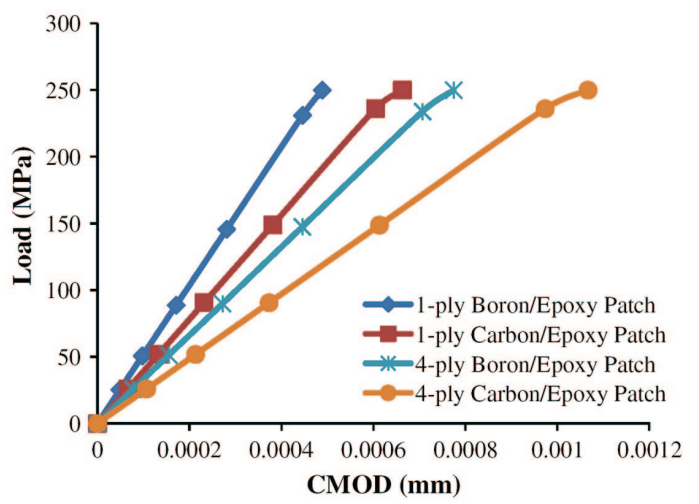

Figure 6. Effect of patch material and number of plies on the crack behavior.

Table 2. Stress intensity factors after composite-patch repair.

\begin{tabular}{lll}
\hline Name & Patch material & $\begin{array}{l}\text { Averaged mode I } \\
\text { stress intensity factor } \\
\text { along crack tip } \\
\left(K_{1}\right)(\mathrm{MPa} \sqrt{\mathrm{mm}})\end{array}$ \\
\hline Cracked bare plate & - & 1623.57 \\
Repaired single patch & Boron/epoxy & 291.35 \\
Repaired double patch & Boron/epoxy & 96.11 \\
\hline
\end{tabular}

a double patch repair as shown in the Figure 7. It illustrates a considerable reduction in the SIF as the patch thickness increases. This is because that double patch is capturing most of the stresses generated by the crack. Simulation results show that the double patch is supporting $73.4 \%$ of the applied load with a patch thickness of $0.6 \mathrm{~mm}$. A thicker patch is desirable; however the bonding efficiency needs to be considered in order to decide an appropriate patch thickness.

\subsection{Effect of adhesive shear modulus}

The adhesive used plays a significant role in bonding a composite patch to the repaired structure. Its main primary purpose is to transmit the loads to the composite patch. Since the adhesive layer in this work is in shear, adhesive shear modulus is one of the two main parameters which affect the efficiency of an adhesive. It is clear from Figure 8 that as the adhesive shear modulus increases, there is a drop in the SIF. However, a high shear modulus will cause the higher shear stress to develop in the adhesive or the substrate. This will inherently cause a failure of adhesion (delamination or breakage) because forces are pulling in opposing directions across the adhesive bond $[15,19,25]$. 
Table 3. Stress intensity factors for different patch materials, number of plies and their orientation.

\begin{tabular}{llcc}
\hline Name & Patch material & $\begin{array}{l}\text { Ply orientation } \\
\text { (with respect } \\
\text { to } x \text {-direction) }\end{array}$ & $\begin{array}{c}\text { Averaged mode I stress } \\
\text { intensity factor along } \\
\text { crack tip }\left(K_{1}\right)(\mathrm{MPa} \text { mm) }\end{array}$ \\
\hline Repaired double patch & 1-Ply boron/epoxy & $0^{\circ}$ & 96.11 \\
Repaired double patch & 1-Ply boron/epoxy & $90^{\circ}$ & 280.1 \\
Repaired double patch & 1-Ply carbon/epoxy & $0^{\circ}$ & 123.02 \\
Repaired double patch & 4-Ply boron/epoxy & $0 / 90 / 90 / 0$ & 148.42 \\
Repaired double patch & 4-Ply carbon/epoxy & $0 / 90 / 90 / 0$ & 188 \\
Repaired double patch & 4-Ply boron/epoxy & $0 / 30 / 30 / 0$ & 123.16 \\
\hline
\end{tabular}

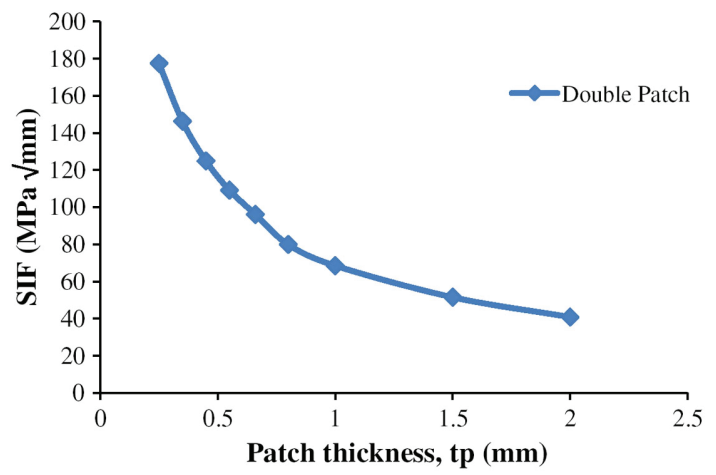

Figure 7. Influence of patch thickness on SIF.

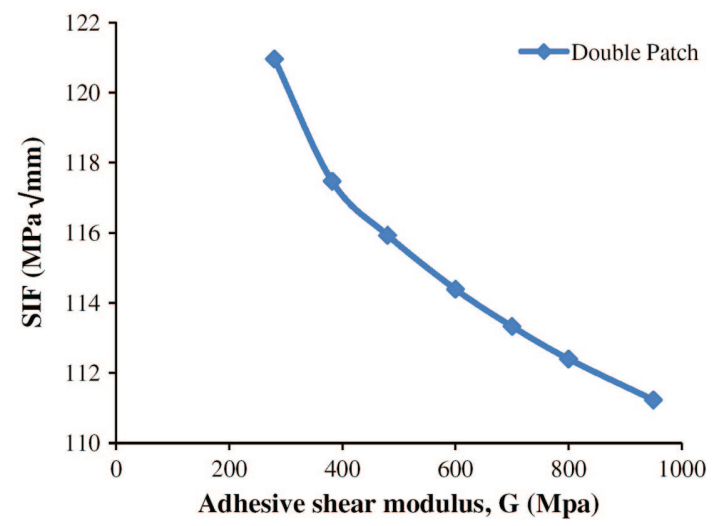

Figure 8. Influence of adhesive shear modulus $(G)$ on SIF.

\subsection{Effect of adhesive thickness}

The thickness of an adhesive affects the performance and cost of the bonding. Figure 9 shows the effect of adhesive thickness on the SIF at the crack tip. There is a considerable increase in the SIF as the thickness of the adhesive increases. This is due to the fact that the adhesive shares more load as the adhesive is thickened. Considering the double patch repair, the adhesive layer with a thickness of $0.12 \mathrm{~mm}$ undertook only $0.08 \%$ load. The maximum shear stress of $37.52 \mathrm{MPa}$ is located on the edge of the adhesive, and contacted with the plate. When a thicker adhesive of $1.5 \mathrm{~mm}$ is applied, it undertook $1.2 \%$ load with a maximum shear stress of $14.00 \mathrm{MPa}$. Arenas et al. [26] also demonstrated that the shear strength is reduced when the adhesive thickness is increased from 0.2 $\mathrm{mm}$ to $0.8 \mathrm{~mm}$. In the contrary, if very thin adhesive is applied, then the load transmitting capability will be good but it might fail because of high shear stress. It is advisable to consider an optimal thickness for the adhesive such that neither of the above cases will occur. The typical structural adhesive thickness used is in the range of $0.2-2.0 \mathrm{~mm}$.

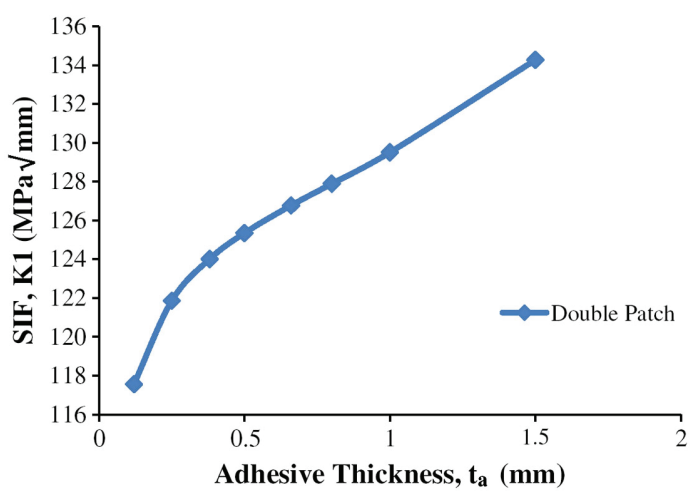

Figure 9. Influence of adhesive thickness on SIF.

\section{Conclusions}

Finite element method has been used to study the crack behavior in an Al substrate with composite-patch repair under uniaxial tension. The effect of material and geometrical properties of the patch and adhesive on the fracture behavior of the joint are investigated in this work and summarized as the following:

- By repairing the cracked plate with bonded composite patches on both sides, there is significant reduction in the stress intensity factor at the crack tip, which is also dependent upon the initial crack size.

- Boron/epoxy patches, compared to carbon/epoxy patches, absorb more dissipated energy thereby reducing the stress intensity and crack mouth opening displacement by $20 \%$.

- There is a three-fold reduction in the SIF when the ply orientation is normal to the crack emanating direction compared to when it is in parallel to the crack propagation direction.

- The patch thickness has a direct influence on the reduction of the SIF up to a certain point.

- A thinner adhesive with high shear modulus will transmit more of the load to the composite patches and reduce the SIF of the substrate. However, it will be prone to delamination and breakage of the joint.

\section{Acknowledgments}

The supports of NASA Nebraska Space Grant and National Science Foundation under Grant No. 0811250 are gratefully acknowledged. The authors also thank Mr. Eric Cutler for correcting the typos and rephrasing sentences. 


\section{References}

[1] Baker AA. Repair of cracked or defective metallic components with advanced fiber composites an overview of Australian work. Compos Struct 1984;2(2):153-81.

[2] Gibson RF. Principles of composite material mechanics. McGrawHill, Inc.; 1994.

[3] Ergun E, Tasgetiren S, Topcu M. Determination of SIF for patched crack in aluminum plates by the combined finite element and genetic algorithm approach. Fatigue Fract Eng Mater Struct 2008;31(11):929-36.

[4] Ouinas D, Hebbar A. Full-width disbonding effect on the repaired cracks in structural panels with bonded composite patches. J Thermoplast Compos Mater 2009;00:1-10.

[5] Dirikolu MH, Aktas A. Analytical and finite element comparisons of stress intensity factors of composite materials. Compos Struct 2000;50(1):99-102.

[6] Anlas G, Santare MH, Lambros J. Numerical calculation of stress intensity factors in functionally graded materials. Int $J$ Fract 2000;104(2):131-43.

[7] Madelpech P, Juaneda S, Pradels M. Bonded composite patch to repair metallic structure: disbond propagation testing and modeling. In: ICAF 2009, bridging the gap between theory and operational practice, proceedings of the 25th symposium of the international committee on aeronautical fatigue, Rotterdam, The Netherlands; 27-29 May 2009. p. 1019-33.

[8] Souiyah M, Muchtar A, Alshoaibi A, Ariffin AK. Finite element analysis of the crack propagation for solid materials. Am J Appl Sci 2009;6(7):1396-402.

[9] Jones R, Peng D, Cairns K, Pitt S. Composite repairs to cracked metallic components - experiment and theory. In: 5th Australasian congress on applied mechanics, ACAM 2007; 10-12 December 2007, Brisbane, Australia.

[10] Aslantas K, Tasgetiren S, Ergun E, Topcu M. Computation of the stress intensity factors and life prediction for repaired cracks. Technol Res: EFMT 2006;3(1):1-10.

[11] Murti V, Valliappan S, Lee IK. Stress intensity factor using quarter point element. J Eng Mech 1984;111(2):203-17.

[12] Henshel RD, Shaw KG. Crack tip elements are unnecessary. Int J Numer Methods Eng 1975;9:495-509.
[13] Barsoum RS. On the use of isoparametric finite elements in linear fracture mechanics. Int J Numer Methods Eng 1976;10(1):25-37.

[14] Megueni A, Bouiadjra BB, Belhouari M. Disbond effect on the stress intensity factor for repairing cracks with bonded composite patch. Comput Mater Sci 2004;29(4):407-13.

[15] Umamaheswar TVRS, Singh R. Modelling of a patch repair to a thin cracked sheet. Eng Fract Mech 1999;62(2-3):267-89.

[16] Anderson TL. Fracture mechanics - Fundamentals and applications. CRC Press, Taylor and Francis Group; 2005.

[17] Wang QY, Pidaparti RM. Static characteristics and fatigue behavior of composite-repaired aluminum plates. Compos Struct 2002;56(2):151-5.

[18] Marioli-riga Z, Xenos D, Vrettos CA. Standard analysis methodology for the stress analysis of repaired aircraft structures with the method of composite patch repair. Appl Compos Mater 2004;11(4):191-203.

[19] Ouinas D, Bouiadjra BB, Achour B, Bender douche N. Modelling of a cracked aluminium plate repaired with composite octagonal patch in mode I and mixed mode. Mater Des 2009;30(3):590-5.

[20] Baker AA, Dutton S, Kelly D. Composite materials for aircraft structures, 2nd ed. American Institute of Aeronautics and Astronautics; 2004.

[21] ABAQUS version 6.9 online documentation. SIMULIA Inc.

[22] Tada H, Paris PC, Irwin GR. The stress analysis of cracks handbook. ASME Press; 2000.

[23] Rose LRF. An application of the inclusion analogy for bonded reinforcements. Int J Solid Struct 1981;17:827-38.

[24] Muller R, Fredell R, Guijt C, Dally R. Experimental verification of Rose's constant $K$ solution in bonded crack patching. Appl Compos Mater 1999;6(4):205-16.

[25] Ouinas D, Bouiadjra BB, Serier B, SaidBekkouche M. Comparison of the effectiveness of boron/epoxy and graphite/epoxy patches for repaired cracks emanating from a semicircular notch edge. Compos Struct 2007;80(4):514-22.

[26] Arenas JM, Narbon JJ, Alia C. Optimum adhesive thickness in structural adhesive joints using statistical techniques based on Weibull distribution. Int J Adhes Adhes 2010;30(3):160-5. 